\title{
Amsterdam as a Sustainable European Metropolis: Integration of Water, Energy and Material Flows
}

\author{
J.P. van der Hoek****, A. Struker** and J.E.M. de Danschutter*** \\ * Delft University of Technology, Faculty of Civil Engineering and Geosciences, Stevinweg 1, 2628 CN Delft, The \\ Netherlands \\ (E-mail: j.p.vanderhoek@tudelft.nl) \\ ** Waternet, Strategic Centre, Korte Ouderkerkerdijk 7, 1096 AC Amsterdam, The Netherlands \\ (E-mail: jan.peter.van.der.hoek@waternet.nl; andre.struker@waternet.nl) \\ ***Waternet, Department of Wastewater Treatment, Korte Ouderkerkerdijk 7, 1096 AC Amsterdam, The \\ Netherlands \\ (E-mail: jacqueline.de.danschutter@waternet.nl)
}

\begin{abstract}
Amsterdam has the ambition to develop as a competitive and sustainable European metropolis. The flows of energy, water and resources within the urban environment have a large potential to contribute to this ambition. The overall mass balances of phosphate, food, water, energy and material imports in the Amsterdam region have already been mapped. Through a transition from a linear usage of resources and waste production without feedbacks of resources, towards a sustainable management of urban resources with circular flows of resources, the sustainability of cities can be increased. This Urban Harvesting Concept can be applied in Amsterdam. The challenge is to operationalize this concept in practice. Two municipal companies in Amsterdam, Waternet and AEB, take initiatives to create closed cycles within their working areas. Waternet is the water company of Amsterdam and surroundings responsible for all water activities. AEB is the company which operates two waste-to-energy plants in Amsterdam. The focus is on water, energy, waste and material flows. Integration of these cycles is also part of the initiatives. These circular flows result in economic benefits and sustainability benefits, either expressed as Ecopoints or $\mathrm{CO}_{2}$-emissions.
\end{abstract}

Keywords

Circular economy; energy; sustainability; urban metabolism; waste; water

\section{INTRODUCTION}

Amsterdam, the capital of the Netherlands, has the policy to develop as a strong and sustainable city in 2040. This is stated in three specific policy documents.

The main policy document is 'The Strategic Vision Amsterdam 2040 Economically Strong and Sustainable' (City of Amsterdam, 2010). In this policy document the vision is that Amsterdam continues to develop further as the core city of an internationally competitive and sustainable European metropolis. The strategy to realize this vision is summarized in five roadmaps: (1) be a creative and varied city to live and work in; (2) have an integrated public transport network; (3) have a high quality urban planning; (4) invest in the recreational green surroundings and the water in Amsterdam; (5) invest in the use of renewable energy.

In the policy document 'Amsterdam: A Different Energy - 2040 Energy Strategy'(City of Amsterdam, 2009) the transition to a sustainable energy supply system is described. This transition is based on three pillars: energy savings, the use of sustainable energy, and the efficient use of fossil fuel. Transition pathways are described for four categories: (1) buildings; (2) clean transport; (3) port and industry; (4) sustainable energy. This should lead to a climate-neutral municipal organization in 2015, 40\% reduction in $\mathrm{CO}_{2}$ emissions in 2025 compared to 1990, and $75 \%$ reduction in $\mathrm{CO}_{2}$ emissions in 2040.

In the policy document 'Amsterdam Really Sustainable 2011-2014' (City of Amsterdam, 2011) three main pillars are distinguished to boost the future of Amsterdam as a vital and attractive city to live and work in: (1) climate and energy; (2) sustainable transport systems and good air quality; (3) sustainable and innovative economy. 
In all three documents the focus is on effective use of resources like raw materials, energy and water. It is stated that a transition should be made from a linear usage of resources and waste production, without feedbacks of resources in terms of quantity and quality, towards o more sustainable management of urban resources. Agudelo-Vera et al. (2012) introduced the Urban Harvesting Concept, in which cities, as consumers of goods and services and producers of waste, transform into resilient cities that produce their own renewable energy and harvest their own internal resources. The concept is shown in Figure 1.

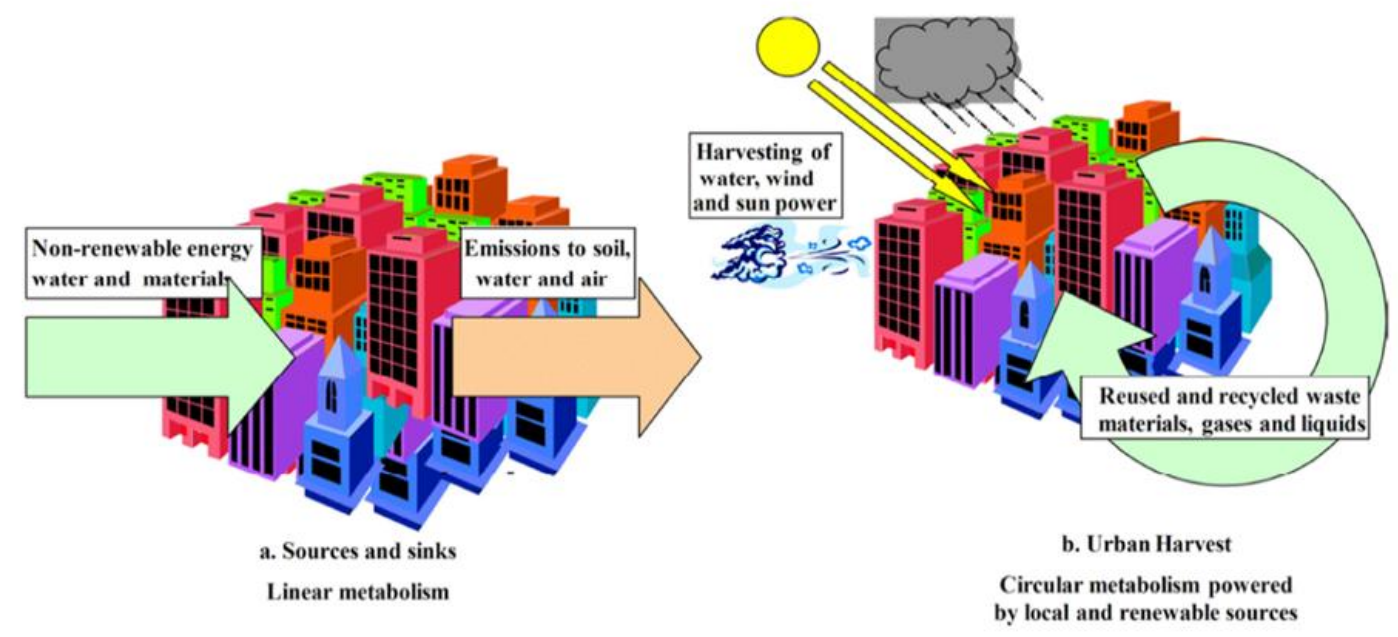

Figure 1. The Urban Harvesting Concept (Agudelo-Vera et al., 2012)

The Urban Harvesting Concept may be very attractive for the city of Amsterdam. In a recent report the current mass balances of the city of Amsterdam have been mapped, to provide the context for which Amsterdam can develop possible directions for circularity (Circle Economy, 2013). Table 1 shows the mass balances of the Amsterdam area. It shows which materials and resources move through the city.

Table 1. The flow of materials and resources through the Amsterdam area

\begin{tabular}{ll}
\hline Materials and resources & Flow \\
\hline Phosphate & 95,000 ton/year \\
Food & 500,000 ton/year \\
Water & 44 million m$^{3} /$ year \\
Energy & 97,0000 Mtoe/year* \\
Material imports & 90 million ton/year \\
\hline
\end{tabular}

$*$ Mtoe $=$ Mega ton oil equivalent; 1 Toe $\approx 42 \mathrm{GJ}$

The challenge in the Urban Harvesting Concept is to transform these linear flows to circular flows. The combination of circular flows and economy leads to the Circular Economy Concept, as described by the Ellen MacArthur Foundation (2012) in the study towards the Circular Economy. This may give a boost to circular activities and may create many public-private initiatives in the chain of products. For The Netherlands an economic benefit of $€ 7.3$ billion and an increase of 54,000 jobs is foreseen (Bastein et al., 2013). This is the Dutch specification of the study towards the Circular Economy by the Ellen MacArthur Foundation.

Two municipal companies in Amsterdam, Waternet and AEB Waste to Energy Company are developing specific initiatives in Amsterdam to make the transition from linear to circular flows. Waternet is the water cycle company of Amsterdam and surroundings, responsible for the water 
management. The activities of Waternet concern drinking water supply, sewerage, wastewater treatment, surface water management, groundwater management, control of the canals in Amsterdam and flood protection.

Some key figures of Waternet are presented in Table 2. The AEB Waste to Energy Company operates two waste-to-energy plants, is responsible for the collection and reuse of hazardous waste, and participates in the exploitation of a city heat network. Some key figures of AEB Waste to Energy Company are presented in Table 3.

In this paper the initiatives of both these municipal companies will be described to illustrate how specific companies can contribute to the operationalization and realization of the rather abstract ambition of the city of Amsterdam to be a sustainable European metropolis in 2040, embracing the principles of the Urban Harvesting Concept.

Table 2. Key figures Waternet

\begin{tabular}{ll}
\hline Customers & 1.2 million \\
Drinking water production & 90 million $\mathrm{m}^{3} /$ year \\
Drinking water treatment plants & 2 \\
Drinking water transport and distribution & $3,440 \mathrm{~km}$ \\
Wastewater treatment & 125 million m $3 /$ year \\
Wastewater treatment plants & 12 \\
Sewerage & $4,000 \mathrm{~km}$ \\
Dikes & $800 \mathrm{~km}$ \\
Nature resources & 4,200 hectares \\
\hline
\end{tabular}

Table 3. Key figures AEB Waste to Energy company

Operational performance

Waste processed

1.5 million tons

Energy supplied

1.0 million $\mathrm{MWh}+600 \mathrm{TJ}$

Metals recovered (non) ferrous

27,000 tons

Environmental performance

Electrical net efficiency

$>30 \%$

Avoided $\mathrm{CO}_{2}$ emission

700,000 ton $\mathrm{CO}_{2}$-eq/year

\section{METHODS}

The initiatives of Waternet and AEB Waste to Energy Company were divided in two groups. The first group concerns initiatives which focus on one cycle: either water, energy, waste or raw materials. The second group concerns initiatives which focus on integration of these cycles.

For several initiatives the effects in terms of avoided greenhouse gas emissions and the environmental impact was calculated. Greenhouse gas emissions have been calculated based on the international Greenhouse Gas Protocol (WRI \& WBCDS, 2004). For determining the environmental impacts the LCA methodology described by Goedkoop and Spriensma (2000) was followed.

\section{RESULTS AND DISCUSSIONS}

\section{Single cycle initiatives}

\section{Reuse of calcite in drinking water softening}

In the Netherlands about $50 \%$ of the drinking water is treated with the pellet softening process for reasons of public health (copper and lead solubility), costs, environmental benefits and customer 
comfort (Hofman et al., 2007). In the drinking water treatment plants of Waternet all water is softened from $2.25 \mathrm{mmol} / \mathrm{l}$ to $1.5 \mathrm{mmol} / \mathrm{l}$. By dosing caustic soda in an upflow fluidized bed reactor, filled with garnet sand, calcium carbonate crystallizes on the garnet grains and calcium carbonates pellets are produces as a by-product (Graveland et al., 1983; Van der Veen and Graveland, 1988). These pellets are applied as a (secondary) raw material in industries such as the construction, agricultural and mineral-resource sector. However, the garnet grain inside the pellet inhibits the application in high potential market segments such as glass and paper. In addition, the garnet sand originates from Australia and thus transport of this material to Amsterdam causes a negative environmental impact.

To avoid the use of garnet sand, and to enhance the reuse of the full grown pellets, a closed loop is introduced in the process (Schetters, 2013). Figure 2 shows the principle. After a first start-up of the process with calcite granules from Italy instead of garnet sand, a part of the full grown calcite pellets which has to be removed from the reactors, about $12 \%$, is grinded and sieved. These grinded calcite grains are used as seeding material instead of garnet sand. The remaining $88 \%$ can be used in other industries. Due to the single component composition the options for reuse are much larger.

For Waternet this approach has both environmental and financial benefits. The cost savings are $€$ 109,250 /year $(0.4 \%$ of the yearly drinking water treatment costs of Waternet) and the reduction in environmental impact is 39,900 Ecopoints/year (5\% of the total environmental impact of the drinking water treatment of Waternet).

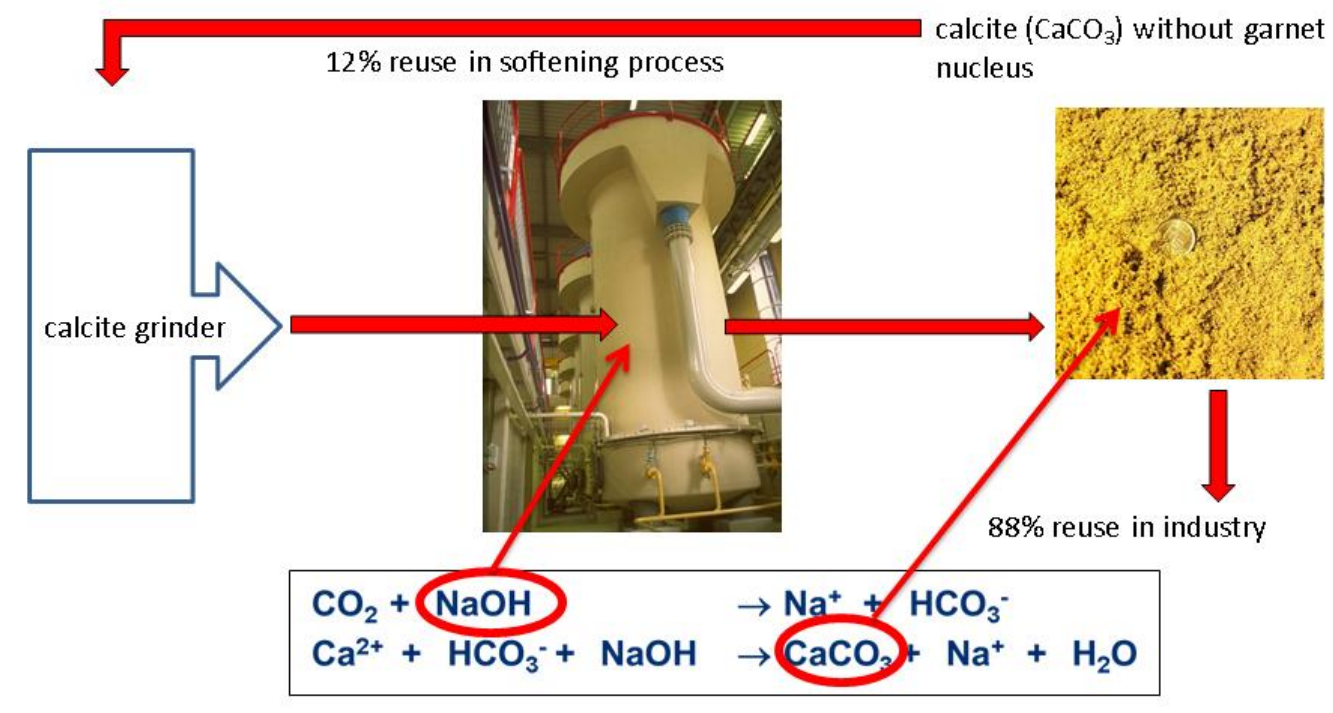

Figure 2. Reuse of calcite in the pellet softening process

\section{Struvite recovery from wastewater}

In the wastewater treatment plant 'Amsterdam West', which has a capacity of 1 million population equivalents, a phosphate recovery step will be introduced in the sludge line. At the moment this plant has problems with blockades of buffers and pipes by struvite precipitation (magnesium ammonium phosphate). At the same time it is known that phosphate is being depleted, as the natural recycling of phosphorous is a very slow process. To avoid operational problems and to recover phosphate, a phosphate recovery process will be introduced in the sludge line of this plant. This process is based on the addition of magnesium chloride $\left(\mathrm{MgCl}_{2}\right)$ to digested sludge during aeration with compressed air and formation of struvite $\left(\mathrm{NH}_{4} \mathrm{MgPO}_{4} \cdot 6\left(\mathrm{H}_{2} \mathrm{O}\right)\right)$. The plant will treat $2,000 \mathrm{~m}^{3}$ sludge per day, and about 1,000 tons struvite will be produced per year. The investment costs are $€$ 4 million, while the expected savings are $€ 400,000 /$ year. Introduction of this process in the 
wastewater treatment plant has also an environmental benefit. It will lower the greenhouse gas emissions with 1,210 ton $\mathrm{CO}_{2}$-eq/year (Klaversma et al,. 2013).

\section{Cellulose recovery from wastewater}

Cellulose fibres, originating from toilet paper, may be a potential resource which could be recovered easily from wastewater by sieving (Ruiken et al., 2013). At the relatively small wastewater treatment plant 'Blaricum', operated by Waternet, fine-mesh sieves have been introduced as pre-treatment for municipal biological wastewater treatment. First results show that these fibres can be removed efficiently from the influent with a high recovery and purity. The cellulose may be reused as biofuel, used in asphalt production, used in the paper industry, or used for the production of bio plastics. The overall energy use of the wastewater treatment plant including sludge treatment can be decreased by at least $40 \%$ with a payback time of 7 years. As calculated by Ruiken et al. (2013) the potential for Waternet is high. Approximately 1,200,000 persons are connected to the wastewater treatment plants of Waternet. They discharge 12,00015,000 ton toilet paper per year. The total suspended solid mass measured in influents is 32,000 tons per year. This indicates that roughly $40 \%$ of the influent suspended solids could be toilet paper derived cellulose.

\section{Integrated cycle initiatives}

Energy recovery from the water cycle

Energy recovery from the water cycle is an initiative that combines the water cycle with the energy cycle. Water-related energy and related greenhouse gas emissions are important issues in future cities (Kenway et al., 2013). Waternet as a water cycle company manages the whole water cycle. This includes surface water, wastewater, drinking water and surface water. All these different types of water may contain thermal energy (e.g. heated drinking water that becomes wastewater) or chemical energy (e.g. organic material in wastewater). A first inventory was made by Van der Hoek (2012) and Mol et al. (2011). A more detailed study to energy recovery from the water cycle in Amsterdam followed in 2013 (Van der Hoek et al., in press). Figure 3 summarizes the results.

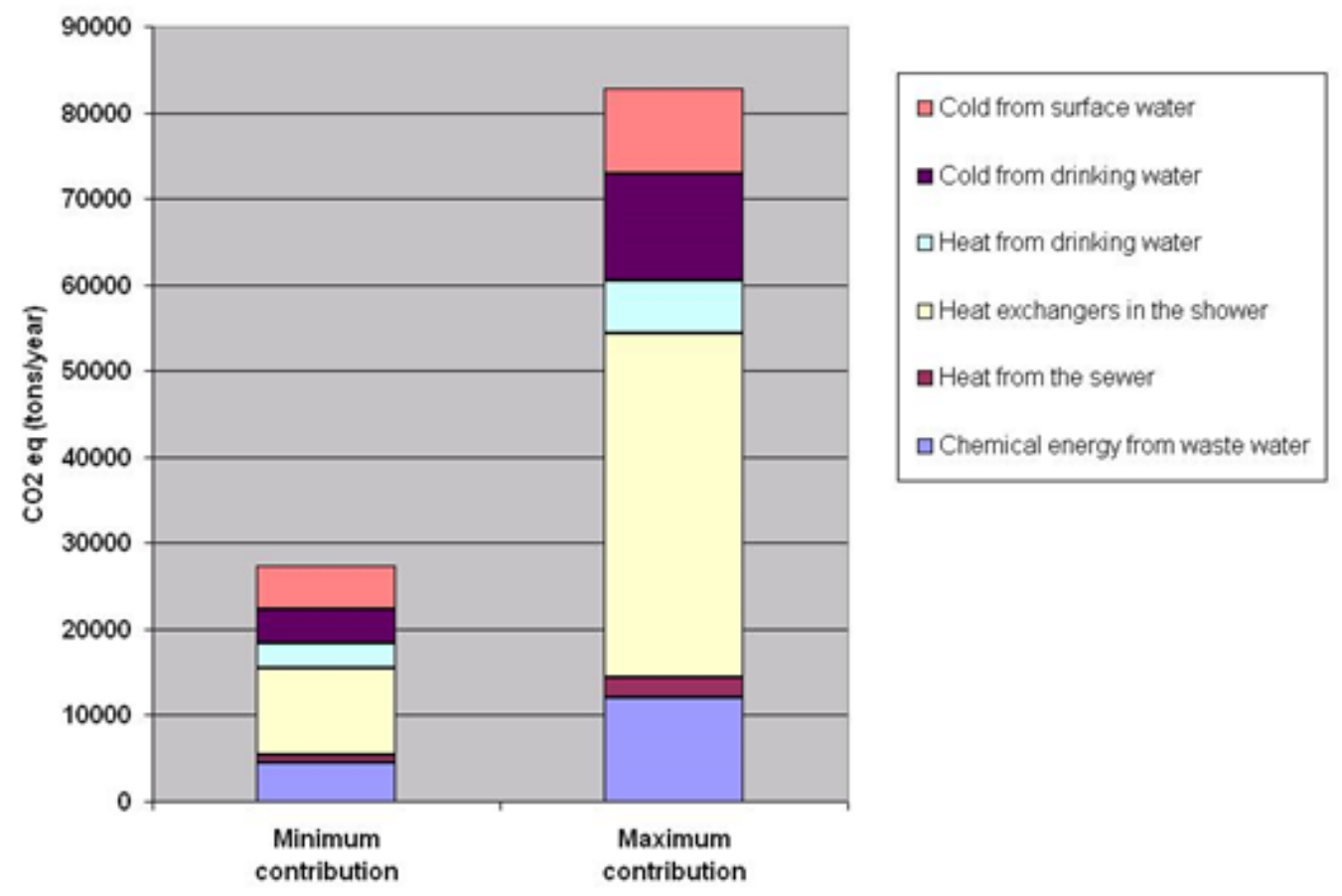

Figure 3. Energy recovery from the water cycle in Amsterdam, expressed as avoided greenhouse gas emissions (Van der Hoek et al,. 2013) 
The research showed that by recovering energy from the water cycle, the use of fossil fuel can be avoided and emission of greenhouse gas can be decreased with 82,800 ton $\mathrm{CO}_{2}$-eq/year in a maximum scenario and 27,300 ton $\mathrm{CO}_{2}$-eq/year in a minimum scenario. In the minimum scenario it is assumed that only projects with a positive business case will be realized, and that not all reductions in greenhouse gas emissions can be contributed to Waternet, as projects will be realized in co-operation with partners. Waternet has the ambition to operate climate neutral in 2020 which requires a compensation of greenhouse gas emissions of 53,000 ton $\mathrm{CO}_{2}$-eq/year. The target of Amsterdam to reduce greenhouse gas emissions with $40 \%$ by 2025 (City of Amsterdam, 2009) implies a reduction of 3,100,000 ton $\mathrm{CO}_{2}$-eq/year. So, recovery of energy from the water cycle may result in a climate neutral Waternet and may contribute $0.9-2.7 \%$ to the ambition of the city of Amsterdam.

Incineration of biogas and sludge at the waste to energy plant

Integration of the water cycle, waste cycle and energy cycle is already practiced in Amsterdam at full scale (Van der Hoek, 2010). The wastewater treatment plant 'Amsterdam West' operated by Waternet and the waste-to-energy plants operated by AEB Waste to Energy Company are neighbours. This has been exploited through an exchange of flows between these plants with huge environmental benefits, shown in Figure 4. In the wastewater treatment plant 25,000 $\mathrm{m}^{3} /$ day biogas is produced. Also sewage sludge is produced, while sewage sludge from other wastewater treatment plants of Waternet is transported to the wastewater treatment plant 'Amsterdam West'. In total this amounts to 100,000 ton sewage sludge/year. Both biogas and sewage sludge are burned in the waste-to-energy plant. Energy produced is used at the wastewater treatment plant: 20,000 $\mathrm{MWh} /$ year electricity and 50,000 GJ/year heat. With this integration the use of 1.8 million $\mathrm{m}^{3} /$ year natural gas at the wastewater treatment plant can be avoided, resulting in an avoided greenhouse gas emission of 3,200 ton $\mathrm{CO}_{2}$-eq/year.

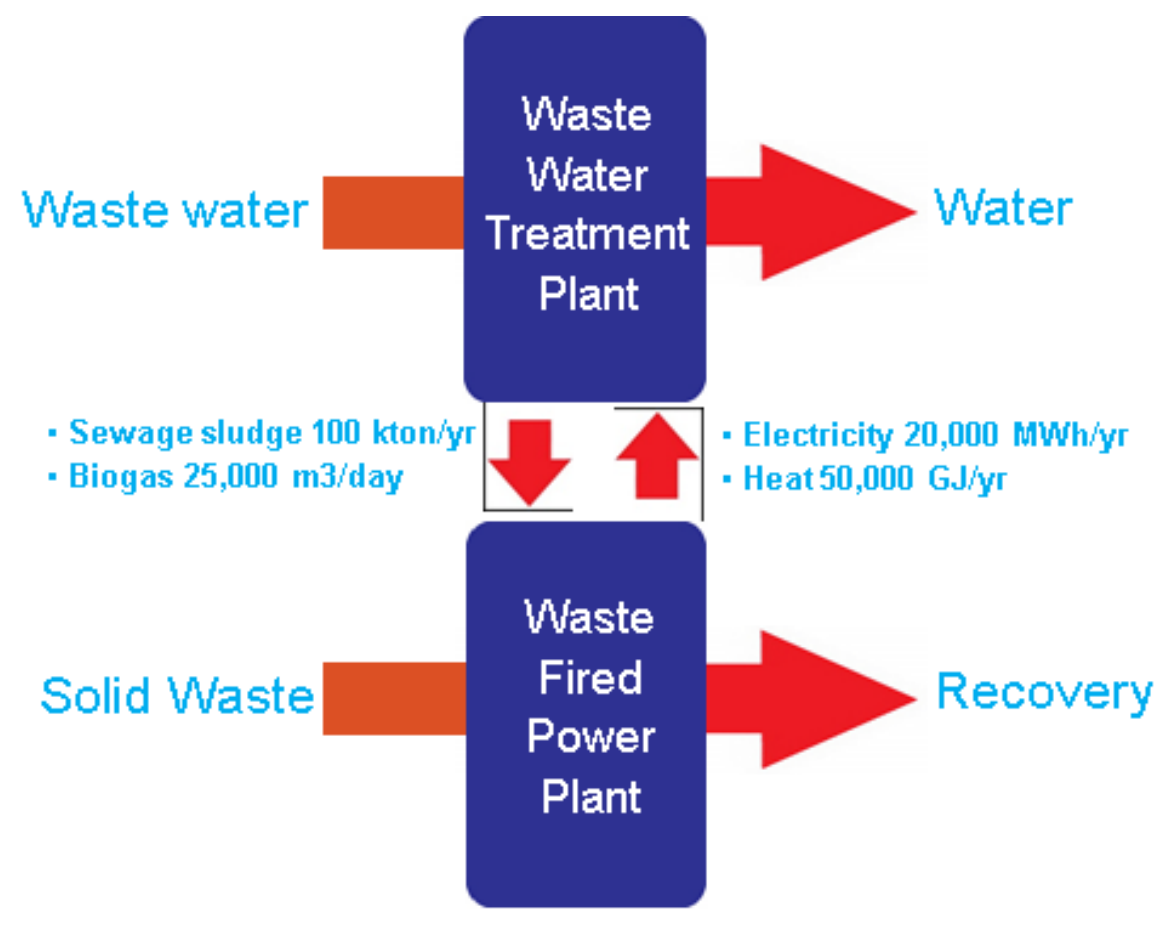

Figure 4. Integration of water, energy and waste: co-operation between wastewater treatment plant 'Amsterdam West' and waste-to-energy plant AEB 
From biogas production to flue gas treatment

Figure 5 shows an integration of cycles covering wastewater, drinking water, transport, building materials and energy production. It has not yet been established in practice but is an nice example how all these cycles may be combined into an integrated system.

The cycle starts with wastewater treatment. Taking into account all 12 wastewater treatment plants operated by Waternet, the maximum biogas production is $35,500 \mathrm{Nm}^{3} /$ day which contains $65 \% \mathrm{CH}_{4}$ and $35 \% \mathrm{CO}_{2}$ (Van der Hoek, 2011). As described above, part of the biogas, 25,000 $\mathrm{Nm}^{3} /$ day, is burned at the wastewater treatment plant 'Amsterdam West', but the other part, $10,500 \mathrm{Nm}^{3} /$ day, can be transferred to Green Gas, which can be used as fuel for cars. In the production of Green Gas from biogas the $\mathrm{CH}_{4}$ content is increased to $88 \%$ with an efficiency of $95 \%$, which implies that 0.7 $\mathrm{m}^{3}$ Green Gas can be produced from $1 \mathrm{~m}^{3}$ biogas. The remaining part is $\mathrm{CO}_{2}$. So, the biogas production of $10,500 \mathrm{Nm}^{3} /$ day can be converted to $7,350 \mathrm{Nm}^{3} /$ day Green Gas as fuel for cars and $3,150 \mathrm{Nm}^{3} /$ day $\mathrm{CO}_{2}$. With a density of $1.986 \mathrm{~kg} / \mathrm{m}^{3}$ this results in a $\mathrm{CO}_{2}$ production of 2,283 ton $\mathrm{CO}_{2} /$ year.

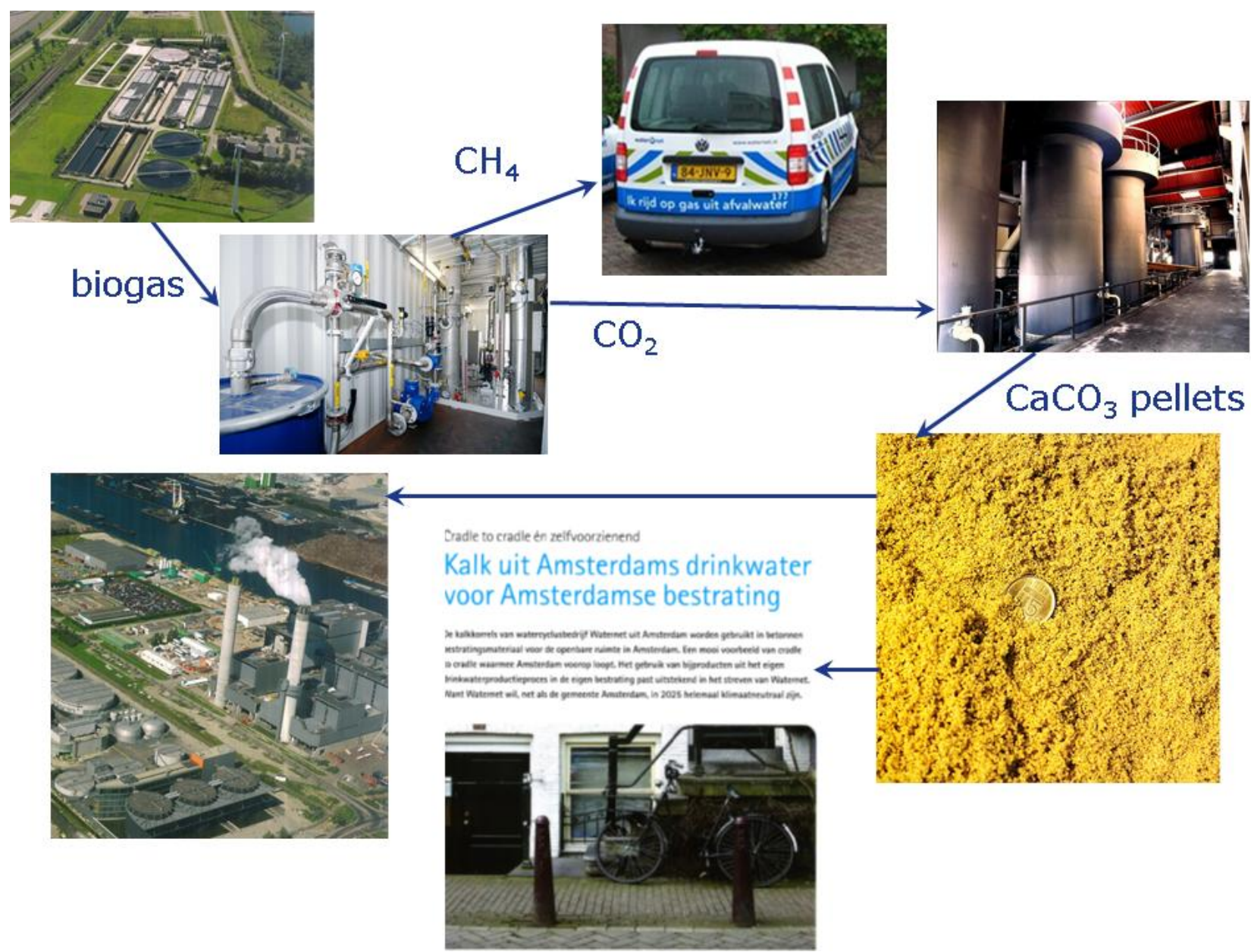

Figure 5. A future perspective of cycle integration

Then the next integration follows: this $\mathrm{CO}_{2}$ can be used in the pellet softening process. In the pellet softening process, the $\mathrm{pH}$ of the water has to be lowered when the water leaves the reactors. Normally this is done with $\mathrm{HCl}$, but an alternative is the use of $\mathrm{CO}_{2}$. In the pellet softening process in the drinking water treatment plants of Waternet approximately 763 ton $\mathrm{CO}_{2} /$ year will be needed for this $\mathrm{pH}$ correction, replacing the use of 1,745 ton $\mathrm{HCl} /$ year $(33 \mathrm{~m} \%)$. A first calculation showed that this will result in a cost reduction of $€ 200,000$ /year and a reduction in environmental impact of 
30,000 Ecopoints/year. In the pellet softening process calcite pellets are produced. At the plants of Waternet the production is approximately 6,790 ton/year. This material can be reused for $12 \%$ in the pellet softening process itself, while the remaining $88 \%$ can be reused in different ways. Attractive for the city of Amsterdam is to use this material in road construction. The link with energy production can be made by using this material in the waste-to-energy plant for flue gas treatment.

Although not a really closed system, different flows are connected in this example. Instead of waste materials, the different cycles produce resources which can be used in other cycles.

\section{CONCLUSIONS}

Municipal companies can be important players to develop cities towards a resilient and sustainable future, characterized by circular flows of water, energy, waste and materials. In Amsterdam this is operationalized by the water cycle company Waternet and the waste-to-energy company AEB. Through the development of initiatives, focusing on recovery and reuse of waste, energy and raw materials, a substantial contribution can be made to the target of Amsterdam. Both the closing cycle in one domain, and integration of cycles from different domains, have huge potentials to realize the ambition of Amsterdam to develop as a sustainable European metropolis.

\section{REFERENCES}

Agudelo-Vera C.M., Leduc W.R.W.A., Mels A.R. and Rijnaarts H.H.M. (2012). Harvesting urban resources towards more resilient cities. Resources, Conservation and Recycling, 64, 3-12.

Bastein T., Roelofs E., Rietveld E. and Hoogendoorn A. (2013). Kansen voor de circulaire economie in Nederland (Chances for the circular economy in The Netherlands). TNO-report TNO 2013 R10864, Delft, The Netherlands.

City of Amsterdam (2009). Amsterdam: A Different Energy - 2040 Energy Strategy, Report City of Amsterdam, Klimaatbureau, Amsterdam, The Netherlands.

City of Amsterdam (2010). Structuurvisie Amsterdam 2040 Economisch sterk en duurzaam (Structural Vision Amsterdam 2040 Economically strong and sustainable), Report City of Amsterdam, Physical Planning Department, Amsterdam, The Netherlands.

City of Amsterdam (2011). Amsterdam Beslist Duurzaam - Duurzaamheidsprogramma 2011/2014 (Amsterdam Really Sustainable - Sustainability Program 2011/2014), Report City of Amsterdam, Amsterdam, The Netherlands.

Circle Economy (2013). Circular Amsterdam - Opportunities and Action Points, Report City of Amsterdam/Circle Economy, Amsterdam, The Netherlands.

Ellen MacArthur Foundation (2012). Towards the circular economy. McKinsey \& Company. http://www.ellenmacarthurfoundation.org/business/reports (accessed 6 October 2013).

Goedkoop M.J. and Spriensma R. (2000). The Eco-Indicator 99: A Damage Oriented Method for Life Cycle Assessment, Report Ministry of Housing, Spatial Planning and the Environment (VROM)/Pré Consult, Amersfoort, The Netherlands.

Graveland A., Dijk J.C. van, Moel P.J. de and Oomen J.H.C.M. (1983). Water softening by means of pellet reactors: developments in The Netherlands. Proceedings of the 1983 AWWA Annual 
Conference, Las Vegas, NV, USA, 149-166.

Hoek J.P. van der (2010). Energie in de watercyclus (Energy in the water cycle). In: Energie uit water: hype of kans? (Energy from water: hype or chance?), $62^{\text {nd }}$ Course in Drinking Water and Wastewater Delft University of Technology, J.C. van Dijk, A.R.D. Verliefde and H. van der Laan (eds), Water Management Academic Press, Delft, The Netherlands, pp. 37-45.

Hoek J.P. van der (2011). Energy from the water cycle: a promising combination to operate climate neutral. Water Practice \& Technology 6 (2).

Hoek J.P. van der (2012). Towards a climate neutral water cycle. Journal of Water and Climate Change, 3 (3), 163-170.

Hoek J.P. van der, Hartog P. and Jacobs E. (in press). Coping with climate change in Amsterdam a watercycle perspective. Journal of Water and Climate Change.

Hofman J., Kramer O., Hoek J.P. van der, Nederlof M. and Groenendijk M. (2007). Twenty years of experience with central softening in The Netherlands: Water quality - Environmental benefits Costs. Water21, February, 21-24.

Kenway S., McMahon J., Elmer V., Conrad S. and Rosenblum J. (2013). Managing water-related energy in future cities - a research and policy roadmap. Journal of Water and Climate Change, 4 (3), 161-175.

Klaversma E., Helm A.W.C. van der and Kappelhof J.W.M.N. (2013). The use of life cycle assessment for evaluating the sustainability of the Amsterdam water cycle. Journal of Water and Climate Change, 4 (2), 103-109.

Mol S.S.M., Kornman J.M., Kerpershoek A.J. and van der Helm A.W.C. (2011). Opportunities for public water utilities in the market of energy from water. Water Science \& Technology, 63 (12), 2909-2915.

Ruiken C.J., Breuer G., Klaversma E., Santiago T. and van Loosdrecht M.C.M. (2013). Sieving wastewater - Cellulose recovery, economic and energy evaluation. Water Research, 47, 43-48.

Schetters M.J.A. (2013). Grinded Dutch calcite as alternative in pellet softening. MSc Thesis, Department Water Management, Delft University of Technology, Delft, The Netherlands.

Veen C. van der and Graveland A. (1988). Central softening by crystallization in a fluidized-bed process. Journal American Water Works Association, 80 (6), 51-58.

WRI \& WBCSD (2004). The Greenhouse Gas Protocol - A Corporate Accounting and Reporting Standard 2004 Revised Edition. World Resources Institute, Washington, DC/World Business Council for Sustainable Development, Geneva, Switzerland. 